\title{
From Platelet-Rich Plasma to Advanced Platelet-Rich Fibrin: Biological Achievements and Clinical Advances in Modern Surgery
}

\author{
Andrea Caruana ${ }^{1}$ Daniele Savina ${ }^{1} \quad$ José Paulo Macedo ${ }^{1}$ Sandra Clara Soares ${ }^{2}$
}

${ }^{1}$ Faculty of Health Sciences, School of Dentistry, Fernando Pessoa University, Porto, Portugal

2Biomedical Research Center, Fernando Pessoa Energy, Environment and Health Research Unit, Faculty of Health Sciences, Fernando Pessoa University, Porto, Portugal

\author{
Address for correspondence Sandra Clara Soares, PhD, Faculty \\ of Health Sciences, Fernando Pessoa University, R. Carlos da Maia, \\ 296 Porto, Portugal (e-mail: sandra@ufp.edu.pt).
}

\begin{abstract}
Keywords

- advanced platelet-rich fibrin

- fibrin

- plasma rich in growth factors

- platelet concentrates

- platelet growth factors

- platelet-rich fibrin

- platelet-rich plasma

- tissue regeneration

In the past 20 years, the platelet concentrates have evolved from first-generation products, i.e., platelet-rich plasma (PRP) and plasma rich in growth factors to the second-generation products such as leukocyte-platelet-rich fibrin (L-PRF) and advanced platelet-rich fibrin (A-PRF). These autologous products with a higher leukocyte inclusion and flexible fibrin mesh act as a scaffold to increase cellular migration in the angiogenic, osteogenic, and antimicrobial potential of these biomaterials in tissue regeneration. In the second-generation platelet concentrates, the protocols are easier, cheaper, and faster with an entire physiological fibrin matrix, resulting in a tridimensional mesh, not as rigid as one of the first generations. This allows the slow release of molecules over a longer period of time and triggers the healing and regenerative process at the site of injury. The potential of A-PRF to mimic the physiology and immunology of wound healing is also due to the high concentration of growth factors released as follows: vascular endothelial growth factor, platelet-derived growth factor, transforming growth factor- $\beta$, and anti-inflammatory cytokines that stimulate tissue cicatrization, vessels formation, and bone cell proliferation and differentiation. Furthermore, the number of neutrophils and monocytes/macrophages is higher releasing important chemotactic molecules such as chemokine ligand-5 and eotaxin. Thus, L-PRF and A-PRF have been used, especially in implantology, periodontology, and maxillofacial surgery. Future clinical applications include tissue regeneration/ grafts, ulcers/skin necrosis in the diabetic patient and others, plastic surgery, and even musculoskeletal lesions.
\end{abstract}

\section{Introduction}

Platelet concentrates are products that result from the centrifugation of a blood sample. They concentrate platelets, fibrin, and leukocytes (depending on the used protocol) converting them into a clinical and useful form.

With the knowledge of the biological features of the concentrates, the initial protocols evolved from the platelet concentrates of first generation that include platelet-rich plasma (PRP) and plasma rich in growth factors (PGRF) to the second-generation concentrates. These ones include protocols such as leukocyte-platelet-rich fibrin (L-PRF) and advanced platelet-rich fibrin (A-PRF). The substantial evolution between the first- and second-generation platelet concentrates is based on the principle that in the second-generation ones, there is no blood manipulation with additives and they remove the anticoagulants from the centrifugation protocol. ${ }^{1}$

The biological and clinical properties of these second-generation platelet concentrates make them highly attractive to
DOI https://doi.org/ 10.1055/s-0039-1696585 ISSN 1305-7456.
License terms

(요 (1) $\odot \circledast$ 
use in regenerative medicine. In the past decades, they were used mainly in the dentistry field to speed revascularization of damaged tissues and bone regeneration before implant placement. Other oral applications include periodontology, maxillofacial surgery such as gingival recession, intrabony defects, alveolar filling postextraction, and sinus lifting. ${ }^{2}$ Nowadays, the autologous platelet concentrates are used not only in dentistry but also for ulcers/skin necrosis, plastic and reconstructive surgery, and even musculoskeletal lesions. ${ }^{3}$

The success of the platelet concentrates depends on the platelet concentration, the number/type of leukocytes entrapped in the fibrin membrane, and also of the release of bioactive molecules at the sites of injury that will trigger the regenerative process. ${ }^{4}$ Growth factors released include vascular endothelial growth factor (VEGF), platelet-derived growth factor (PDGF), transforming growth factor- $\beta$ (TGF- $\beta$ ), epidermal growth factor (EGF), insulin-like growth factor (IGF-I), hepatocyte growth factor (HGF), cytokines such as interleukin-1 (IL-1), interleukin-6 (IL-6), interleukin-4 (IL-4), and interleukin-10 (IL-10), and chemotactic molecules such as chemokine ligand-5 (CCL5) and eotaxin. Thus, platelet concentrates such as A-PRF have all the biological features to induce an optimal healing. ${ }^{5}$

\section{Platelet Concentrates}

\section{Characteristics of Platelet-Rich Plasma, Plasma rich in Growth Factors, Platelet-Rich Fibrin, and Advanced Platelet-Rich Fibrin}

In modern tissue regeneration, the evolution of the platelet concentrates was directed toward less time, better quality, and less invasiveness using autologous products and reducing the risk of rejection from the patient. The fact that the second-generation concentrates respect the European Directive 2004/03/CE can also account for another characteristic that compares the effectiveness of first- and second-generation platelets, there is no manipulation of the patients' blood, so the protocol is also simple and cheaper. ${ }^{6.7}$

\section{Platelet-Rich Plasma}

Inside the PRP family, a clarification is necessary to allow comparing with other recent protocols. The protocol developed by Jo et $\mathrm{al}^{8}$ uses the same amount of blood as the others of first- and second generations $-9 \mathrm{~mL}$. It is considered a first-generation concentrate using calcium glutamate/bovine thrombin to activate coagulation and an anticoagulant solution of citrate phosphate dextrose adenine (CPDA). There is a first centrifugation (900 rpm/5 minutes) to separate the red cells from the white cells, and three layers are obtained-a superior one rich in platelet and white cells, a medium one of buffy coat, and an inferior layer with the red cells. After collecting the two superior layers, a second centrifugation at $1500 \mathrm{rpm} / 15$ minutes excludes the red cells. Both centrifugations use plastic tubes and the final result is $2 \mathrm{~mL}$ of gel containing the $\times 4.2$ increase in the initial number of platelets. ${ }^{8,9}$

\section{Plasma Rich in Growth Factors}

Furthermore, the first-generation concentrate with anticoagulants (sodium citrate) and coagulation activators (calcium chloride) and the final product is obtained after an $1850 \mathrm{rpm} / 8$ minutes centrifugation also in plastic tubes. After that, three layers of blood include a superior one divided into platelet-poor plasma (PPP) and PRP, a medium one with buffy coat, and the inferior one with the red cells. Depending on the clinical use, we can have different forms of presentation and the most used in regenerative medicine is the fibrin mesh induced by PPP that forms after 15 to 20 minutes. ${ }^{10}$

\section{Leukocyte-Platelet-Rich fibrin}

This is a second-generation platelet concentrate, in which the final product is obtained by a total physiologic process. For Inchingolo et al, ${ }_{11}^{11}$ the lack of "additives" allows the natural activation of the platelets and coagulation when in contact with the tube. This last one is made from glass, not plastic because according to Jianpeampoolpol et $a l,{ }^{12}$ the silica from the glass is a natural coagulation inducer. The fibrinogen initially concentrated in the superior layer of the tube when in contact with the thrombin is converted into fibrin that will imprison the platelets: a quick process between the harvest and blood centrifugation. According to Marrelli and Tatullo, ${ }^{13}$ PRF has a mesh of fibrin that allows cellular migration and a slow release of growth factors essential for tissue regeneration. The final product is originated after centrifugation at $2700 \mathrm{rpm} / 12$ minutes with the fibrin mesh in the middle of the tube between the noncellular and cellular plasma (with platelets, leukocytes, and fibrin).

\section{Advanced Leukocyte-Platelet-Rich Fibrin}

In this second-generation platelet concentrate, the fibrin mesh is obtained using lower $\mathrm{G}$ forces $(1500 \mathrm{rpm} / 14 \mathrm{~min}-$ utes) that clinically translate in an increased concentration of growth factors and neoangiogenic potential. ${ }^{14,15}$ They also use glass tubes for centrifugation, and according to Dohan Ehrenfest et $a l,{ }^{14}$ the changes in the speed and time in the centrifugation protocol result in a shorter membrane, lighter, and narrower with the increased capacity of cell imprison. Changing the centrifugation protocol to Choukroun's PRF translated in the change of the leukocyte pattern in the fibrin-rich clot: the number of neutrophils increased. ${ }^{16}$

The main characteristics of all the platelet concentrates are summarized in - Table $\mathbf{1}$.

\section{Platelet Growth Factors}

The biological properties of the platelet concentrate explore the platelet's function in organism homeostasis, namely, the fibrin coagulation and tissue regeneration. Such potential is due to growth factors such as VEGF, PDGF, TGF- $\beta$, EGF, IGF-I, and HGF. After centrifugation, all these factors contribute to soft- and hard-tissue regeneration and wound healing after tissue injury ${ }^{17,18}$ (-Table 2).

\section{Leukocytes and the Inflammatory Process}

As mentioned before, the first goal in tissue regeneration was to separate the plasmatic components to obtain a rich-platelet concentrate. Afterward, it was observed that besides platelets the inclusion of other components such as leukocytes could improve the healing process. Thus, leukocytes release 
Table 1 Biological comparison between the first- and second-generation platelet concentrates

\begin{tabular}{|c|c|c|c|c|}
\hline Platelet concentrate & PRP8 & PRGF & L-PRF & A-PRF \\
\hline Generation & 1 & 1 & 2 & 2 \\
\hline Anticoagulants use & Yes (CPDA) & $\begin{array}{l}\text { Yes (sodium } \\
\text { citrate) }\end{array}$ & No & No \\
\hline Coagulation activation & $\begin{array}{l}\text { Calcium glutamate/bovine } \\
\text { thrombin }\end{array}$ & Calcium Chloride & No & No \\
\hline $\begin{array}{l}\text { Protocol (rpm/min) } \\
\text { centrifuge tubes }\end{array}$ & $\begin{array}{l}900 / 5+1500 / 15 \text { (plastic } \\
\text { tubes) }\end{array}$ & $\begin{array}{l}1850 / 8 \text { (plastic } \\
\text { tubes) }\end{array}$ & $\begin{array}{l}2700 / 12 \text { (glass } \\
\text { tubes) }\end{array}$ & $1500 / 14$ (glass tubes) \\
\hline Protocol cost & High & High & Low & Low \\
\hline Fibrin membrane & - & Yes & Yes & Yes \\
\hline $\begin{array}{l}\text { Fibrin membrane } \\
\text { formation }\end{array}$ & - & Induced & Physiological & Physiological \\
\hline Leukocytes & Nondetermined & $0 \%$ & $50-65 \%$ & 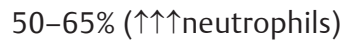 \\
\hline Growth factors & $\sqrt{ }$ & $\sqrt{ } \sqrt{ }$ & $\sqrt{ } \sqrt{ } \sqrt{ }$ & $\sqrt{ } \sqrt{ } \sqrt{ } \sqrt{ }$ \\
\hline Bone regeneration & $\sqrt{ }$ & $\sqrt{ } \sqrt{ }$ & $\sqrt{ } \sqrt{ }$ & $\sqrt{ } \sqrt{ }$ \\
\hline Presentation form & Gel & $\begin{array}{l}\text { Liquid } \\
\text { Clot } \\
\text { Supernatant } \\
\text { Fibrin membrane }\end{array}$ & $\begin{array}{l}\text { Plugs (for alveolar } \\
\text { filling) } \\
\text { Exudate } \\
\text { Fibrin membrane }\end{array}$ & $\begin{array}{l}\text { Plugs (for alveolar filling) } \\
\text { Exudate } \\
\text { Fibrin membrane }\end{array}$ \\
\hline
\end{tabular}

Abbreviations: $\uparrow \uparrow \uparrow$, increased concentration; $\sqrt{ }$, small amount; $\sqrt{ }$, medium amount; $\sqrt{ } \sqrt{ }$, good amount; $\sqrt{ } \sqrt{ } \sqrt{ }$, very good amount; $\sqrt{ } \sqrt{ } \backslash \sqrt{ }$, excellent amount; A-PRF, advanced platelet-rich fibrin; CPDA, citrate phosphate dextrose adenine; L-PRF, leukocyte-platelet-rich fibrin; PRGF, plasma rich in growth factor; PRP, platelet-rich plasma.

VEGF and TGF that, again, improve chemotaxis and angiogenesis. ${ }^{29-31}$ Nowadays, there are in the market first-generation protocols with or without leukocytes and second-generation ones that always include white cells.

Literature results about the impact of leukocytes in the first-generation platelet concentrates revealed heterogeneous results. On the one hand, there is lack of clinical evidence of the positive impact of leukocytes, and on the other hand, some authors claim that the leukocyte exclusion improves the healing process, reducing the inflammatory response modulated by the secretion of metalloproteinases, hydrolases, and proteases. . $^{32,33}$

The second-generation platelet concentrates, namely, L-PRF and A-PRF emerged in the market to overcome the limitations found in the first-generation concentrates. A complete autologous concentrate with a higher leukocyte inclusion in a fibrin mesh (to act as a scaffold) should increase its osteogenic and antimicrobial potential. Following this research new developed protocols also seem to substantiate the positive biological impact of the fibrin in the cells support and migration, inducing rapid tissue regeneration. Besides, there is also an increase in VEGF, TGF production, and anti-inflammatory cytokines that will mediate the inflammatory process. ${ }^{34}$

IL-4 drives Th cell differentiation in a Th2 pattern, inducing activation and proliferation of B-cells. During the inflammatory process, it negatively regulates IL-1 and tumor necrosis factor- $\alpha$, inducing IL-10, another Th2 cytokine. It induces the antagonist of IL-1 receptor contributing to the control of postsurgery pain. ${ }^{1}$ IL-6, according to Kumar and Shubhashi$\mathrm{ni},{ }^{35}$ is a pleiotropic cytokine produced by cells such as fibroblasts, endothelial cells, monocytes, and macrophages, also inducing B- and $\mathrm{T}$ cell differentiation. It is involved in the acute-phase response not only sharing some properties with IL-1 but also inducing IL-1 receptor and a negative feedback in the inflammatory cascade. .6,37 $^{3,3}$

However, there is a lack of clinical studies validating the role of the leukocytes and cytokines in the inflammatory process beginning with inflammation, then proliferation and finally regeneration. There are not enough in vivo studies to support that, when using the platelet concentrates, we are also using M2 (alternatively activated macrophages [anti-inflammatory molecule producer])-polarized macrophages instead of M1 (classically activated macrophages [pro-inflammatory molecules producer]). ${ }^{38,39}$

Tissue repairing requires a strategic collaboration of all leukocytes, epithelial and endothelial cells, fibroblasts, and platelets. In Choukron's A-PRF, the number of leukocytes includes more neutrophils that also can contribute to a proor anti-inflammatory state of the macrophages modulating tissue regeneration. ${ }^{16}$

\section{The Inclusion of Fibrin as a Scaffold}

In platelet concentrates PGRF, L-PRF, and A-PRF, the fibrin mesh represents a big innovation in regenerative tissue processing. The fibrin and the final products from fibrinogen degradation stimulate neutrophil migration and increase chemotaxis, by overexpression of the membrane receptors CD11c/CD18. ${ }^{40}$

In dental tissues regeneration, such as periodontal tissue, the fibrin scaffold supports and acts as a carrier for cells. It is a natural polymer that interacts directly with the cells/tissue, inducing an, almost natural, tissue regeneration. This is one of the foundations of tissue engineering applications. ${ }^{41}$ 
Table 2 Platelet growth factors properties

\begin{tabular}{|c|c|}
\hline Growth factors & Biological action \\
\hline VEGF & $\begin{array}{l}\text { The VEGF was first mentioned by Ferrara and Gerber }{ }^{19} \text { as a signaling protein, angiogenic and with spec- } \\
\text { ificity for the vascular endothelial cells, stimulating chemotaxis and endothelial cell proliferation. Nör } \\
\text { et a }{ }^{20} \text { demonstrate that VEGF also regulates vascular permeability, the main process for the beginning of } \\
\text { angiogenesis and also induces bone tissue regeneration. Thus, Di Alberti et al }{ }^{21} \text { wrote that it is the main } \\
\text { growth factor for tissue regeneration in dentistry implants application }\end{array}$ \\
\hline PDGF & $\begin{array}{l}\text { This growth factor concentrates mainly in the platelets } \alpha \text { - granules, liberated during the coagulation } \\
\text { cascade. Its effect is dependent on other growth factors presence, inducing fibroblast, macrophages, and } \\
\text { other leukocytes chemotaxis. }{ }^{22} \text { According to Caplan and Correa, }{ }^{23} \text { the target of PDGF is mainly the bone } \\
\text { tissue inducing osteoblast chemotaxis, vascular regeneration, and fracture repairing. It is the first growth } \\
\text { factor to be found in a wound, responsible for collagen synthesis in the connective tissue }\end{array}$ \\
\hline TGF- $\beta$ & $\begin{array}{l}\text { As referred by Miyazono, }{ }^{24} \text { this factor as a role in the growth, proliferation, adhesion, and apoptosis of } \\
\text { several cell types being a key player in the inflammatory process. It induces chemotaxis and mitogenesis } \\
\text { of undifferentiated cells to the place of repair activating fibroblasts, osteoblasts, and chondroblasts prolif- } \\
\text { eration. It induces the first step of repairing and extracellular matrix healing }{ }^{25}\end{array}$ \\
\hline EGF & $\begin{array}{l}\text { The EGF promotes chemotaxis and mitogenesis of epithelial, mesenchymal cells and fibroblasts also } \\
\text { inducing tissue regeneration. It stimulates epithelial proliferation in peri-implantar tissues inducing the } \\
\text { formation of the peri-implant junctional epithelium. Thus, its presence together with EGF from saliva } \\
\text { increases in oral surgery } 26\end{array}$ \\
\hline IGF-I & $\begin{array}{l}\text { As referred by Kurten et al, }{ }^{27} \text { IGF-I is synthetized by almost every tissue with increased concentrations in } \\
\text { bone. It mediates growth, differentiation, and cellular transforming and stimulates osteoblasts. It is also } \\
\text { involved in keratinocytes migration and wound healing }{ }^{28}\end{array}$ \\
\hline HGF & $\begin{array}{l}\text { This platelet growth factor regulates the migration and cellular morphogenesis having an important role } \\
\text { in wound repair through its interaction with the mesenchymal epithelium }{ }^{10}\end{array}$ \\
\hline
\end{tabular}

Abbreviations: EGF, epidermal growth factor; HGF, hepatocyte growth factor; IGF-I, insulin-like growth factor; PDGF, platelet-derived growth factor; TGF- $\beta$, transforming growth factor- $\beta$; VEGF, vascular endothelial growth factor.

Aggour and Abd El-Hady ${ }^{42}$ observed in vitro that fibrinbased membranes are better scaffolds for the proliferation of bone cells when compared with collagen membranes. This strong mechanical and polymerization characteristic makes it a more suitable support for regeneration, increasing fibrinogen concentrations, and inducing the formation of a stronger matrix. In PRP, the fibrin mesh is quite "immature" with small diameter fibrils. This mesh supports platelets during surgery but rapidly dissolves like glue, not having the same angiogenic and chemotactic potential of a membrane. ${ }^{40}$

In PRGF, the use of an anticoagulant and a gel agent influences the velocity and polymerization of the membrane, and as a result, it forms a tetra-molecular mesh condensate with an increased quantity of fibrin. Thus, in PGRF, where the use of coagulation activator modifies the thrombin concentrations, the thickening of the fibrin polymers results in the formation of a rigid mesh that favors the sealing of the biological tissues but impairs cellular migration and cytokine release. ${ }^{7}$

In PRF (L-PRF and A-PRF), there is no patient blood manipulation, and the fibrin matrix formation is completely physiological creating a tridimensional mesh. With no manipulation, the thrombin concentrations are lower favoring the cellular imprisonment and molecules deliverance during 10 days. ${ }^{43}$ These cells and the VEGF are crucial for vascular angiogenesis and pathogen elimination avoiding possible contaminations. The spatial confirmation of the fibrin mesh also supports the platelets and stem cells ideal for concentration at the injury/surgery $\operatorname{site}^{44}$ ( Fig. 1)..$^{37,40,45-47}$

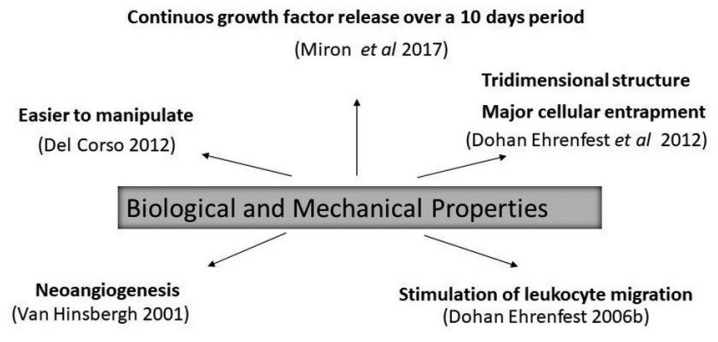

Fig.1 Fibrin: an autologous matrix.

\section{Leukocyte-Platelet-Rich Fibrin and Advanced Platelet-Rich Fibrin: Recent Applications}

All the studies until now reveal that the biological effects achieved depend on the platelet concentration and the number/type of leukocytes entrapped in the fibrin membrane. Thus, the release of bioactive molecules at the sites of injury will trigger the healing and regenerative process. ${ }^{4}$

Recent in vitro studies show that L-PRF ability to potentiate angiogenesis and vasculogenesis at the injury site is mediated not only by the liberation of bioactive molecules but also by the presence of hematopoietic stem cells and endothelial progenitor cells. ${ }^{39}$

The second-generation concentrates L-PRF and A-PRF have a similar level of platelets and cytokines. However, A-PRF releases a significantly higher quantity of growth factors TGF- $\beta$, PDGF, VEGF, and chemotactic molecules CCL-5 and eotaxin, when compared with traditional PRF. ${ }^{43}$ Furthermore, A-PRF 
has an increased number of neutrophils. These inflammatory cells contribute to monocyte/macrophage differentiation, despite the similar total amount of leukocytes. ${ }^{16}$ Thus, A-PRF is an excellent candidate for tissue repair and vessel formation. ${ }^{5}$

The main clinical applications of L-PRF and A-PRF include tissue regeneration in oral and maxillofacial surgery (alone or with bone grafts). In regenerative medicine and dentistry, several clinical studies showed better outcomes with PRF than open-flap debridement, in intrabony periodontal defects. Furthermore, its use together with bone substitutes such as nanohydroxyapatite had a therapeutic effect compared with the substitutes alone. ${ }^{48}$ Osteonecrosis of the jaws can also benefit from L-PRF application: necrotic bone replacement by L-PRF was used as a physical barrier against microorganisms, preventing secondary infections. ${ }^{49}$ PRF can also act in the treatment of ulcers/skin necrosis, plastic surgery, ${ }^{3}$ and even musculoskeletal lesions. ${ }^{50}$

In A-PRF, the release of TGF- $\beta-1$, PDGF, and VEGF and the presence of monocytes/macrophages facilitate wound healing and tissue regeneration. ${ }^{51}$ All of these biological factors were previously associated with a high success in several dentistry areas as follows: periodontal reconstructive surgery, ${ }^{52}$ sinus lift, and implants. ${ }^{53}$ Furthermore, A-PRF can be used with freeze-dried bone allograft improving bone osteogenesis and alveolar stability in the use of implants. ${ }^{54}$

Current clinical trials are evaluating the use of A-PRF in periodontal angular defects. Thus, there are studies focusing the treatment of intrabony defects with PRF, it lacks evidence of the benefit of A-PRF in the same patients..$^{55}$

In orthopaedic surgery, the use of L-PRF with bone cell proliferation/differentiation inducers such as bone morphogenetic proteins- 2 also seems to be a benefit for tissue regeneration. ${ }^{56}$ Furthermore, Crisci et al study the use of L-PRF in ulcers in a diabetic foot and found that treatment improved wound healing with no evidence of infection. ${ }^{57}$ In other types of chronic ulcers such as pressure and venous leg ulcers, the use of L-PRF has also improved healing and cicatrization. ${ }^{3}$

\section{Conclusion}

When analyzing the efficacy in clinical applications has shown in the literature, second-generation platelet concentrates result in more natural protocols, lower costs, and faster time for obtaining a valid clinical product when compared with the first-generation protocols.

When comparing the biological properties, proliferation versus differentiation, L-PRF and A-PRF use a high number of leukocytes, and platelets and growth factors promoting both proliferation and differentiation. L-PRF and A-PRF mimic the physiological process, opposite to the first-generation concentrates that use anticoagulants and coagulation activators that can reduce the positive leukocyte impact in wound healing. The TGF- $\beta$, PDGF, VEGF, eotaxin, and CCL- 5 released by the leukocytes promote local vascularization and tissue repairing, mainly due to the control of the inflammatory process by anti-inflammatory cytokines IL-4, IL-6, and IL-10 also having an antimicrobial potential.
Furthermore, the fibrin scaffold has different physical and biological properties, capturing a higher number of cells, and including stem cells that can differentiate in other autologous cells. In A-PRF, there is an increase not only in the number of neutrophils but also the time of growth factors liberation increases in 10 days. This results in better cellular conduction, migration, angiogenesis, and natural healing of the tissues patient. For these reasons, the potential benefits of leukocyte (mainly inflammatory neutrophils) and fibrin are reciprocal, and they are mutual stimulation "actors" in the healing process.

Nowadays, the L-PRF and A-PRF are used not only in dentistry has coadjuvants in tissue regeneration before implant rehabilitation but also for chronic ulcers, musculoskeletal lesions, plastic surgery, and even orthopaedic surgery. In the future, there is a wide range of clinical applications due to the low costs and rapid healing properties of these concentrates, but still, there is a vast research to be done translating the laboratory results to the clinical practice.

\section{Funding}

None.

\section{Conflict of Interest}

None declared.

\section{Acknowledgments}

The authors would like to thank the Faculty of Health Sciences, School of Dentistry, Fernando Pessoa University, Porto, Portugal, for the help with obtaining all the study materials that allowed Andrea Caruana and Daniele Savina to finish their Masters Degree in Dentistry.

\section{References}

1 Dohan DM, Choukroun J, Diss A, et al. Platelet-rich fibrin (PRF): a second-generation platelet concentrate. Part II: platelet-related biologic features. Oral Surg Oral Med Oral Pathol Oral Radiol Endod 2006a;101(3):e45-e50

2 Gupta SJ, Jhingran R, Gupta V, Bains VK, Madan R, Rizvi I. Efficacy of platelet-rich fibrin vs. enamel matrix derivative in the treatment of periodontal intrabony defects: a clinical and cone beam computed tomography study. J Int Acad Periodontol 2014;16(3):86-96

3 Pinto NR, Ubilla M, Zamora Y, Del Rio V, Dohan Ehrenfest DM, Quirynen M. Leucocyte- and platelet-rich fibrin (L-PRF) as a regenerative medicine strategy for the treatment of refractory leg ulcers: a prospective cohort study. Platelets 2018;29(5):468-475

4 Anitua E, Sánchez M, Zalduendo MM, et al. Fibroblastic response to treatment with different preparations rich in growth factors. Cell Prolif 2009;42(2):162-170

5 Cabaro S, D'Esposito V, Gasparro R, et al. White cell and platelet content affects the release of bioactive factors in different blood-derived scaffolds. Platelets 2018;29(5):463-467

6 Tatullo M, Marrelli M, Cassetta M, et al. Platelet Rich Fibrin (P.R.F.) in reconstructive surgery of atrophied maxillary bones: clinical and histological evaluations. Int J Med Sci 2012;9(10):872-880

7 Giannini S, Cielo A, Bonanome L, et al. Comparison between PRP, PRGF and PRF: lights and shadows in three similar but different protocols. Eur Rev Med Pharmacol Sci 2015;19(6):927-930 
8 Jo CH, Roh YH, Kim JE, Shin S, Yoon KS. Optimizing platelet-rich plasma gel formation by varying time and gravitational forces during centrifugation. J Oral Implantol 2013;39(5):525-532

9 Dhurat R, Sukesh M. Principles and methods of preparation of platelet-rich plasma: a review and author's perspective. J Cutan Aesthet Surg 2014;7(4):189-197

10 Anitua E, Prado R, Sánchez M, Orive G. Platelet-rich plasma: preparation and formulation. Oper Tech Orthop 2012;22:25-32

11 Inchingolo $F$, Tatullo $M$, Marrelli $M$, et al. Trial with platelet-rich fibrin and Bio-Oss used as grafting materials in the treatment of the severe maxillar bone atrophy: clinical and radiological evaluations. Eur Rev Med Pharmacol Sci 2010;14(12):1075-1084

12 Jianpeampoolpol B, Phuminart S, Subbalekh K. Platelet-rich fibrin formation was delayed in plastic tubes. BJMMR 2016;14:1-9

13 Marrelli M, Tatullo M. Influence of PRF in the healing of bone and gingival tissues. Clinical and histological evaluations. Eur Rev Med Pharmacol Sci 2013;17(14):1958-1962

14 Dohan Ehrenfest DM, Del Corso M, Kang BS, et al. The impact of centrifuge characteristics and centrifugation protocols on the cells, growth factors and fibrin architecture of a leukocyte and platelet rich fibrin (L-PRF) clot and membrane. Part 3: comparison of the growth factors content and slow release between the original L-PRF and the modified A-PRF (Advanced Platelet-Rich Fibrin) membranes. Poseido J 2014;2:155-166

15 Choukroun J. Advanced PRF and i-PRF: platelet concentrate or blood concentrate? J Periodontal Med Clin Pract 2014;1:1-3

16 Ghanaati S, Booms P, Orlowska A, et al. Advanced platelet-rich fibrin: a new concept for cell-based tissue engineering by means of inflammatory cells. J Oral Implantol 2014;40(6):679-689

17 Anitua E, Sánchez M, Nurden AT, Nurden P, Orive G, Andía I. New insights into and novel applications for platelet-rich fibrin therapies. Trends Biotechnol 2006;24(5):227-234

18 Stellos K, Kopf S, Paul A, et al. Platelets in regeneration. Semin Thromb Hemost 2010;36(2):175-184

19 Ferrara N, Gerber HP. The role of vascular endothelial growth factor in angiogenesis. Acta Haematol 2001;106(4):148-156

20 Nör JE, Christensen J, Liu J, et al. Up-regulation of Bcl-2 in microvascular endothelial cells enhances intratumoral angiogenesis and accelerates tumor growth. Cancer Res 2001;61(5):2183-2188

21 Di Alberti L, Rossetto A, Albanese M, et al. Expression of vascular endothelial growth factor (VEGF) mRNA in healthy bone tissue around implants and in peri-implantitis. Minerva Stomatol 2013;62(4 Suppl 1):1-7

22 Schmidt MB, Chen EH, Lynch SE. A review of the effects of insulin-like growth factor and platelet derived growth factor on in vivo cartilage healing and repair. Osteoarthritis Cartilage 2006;14(5):403-412

23 Caplan AI, Correa D. PDGF in bone formation and regeneration: new insights into a novel mechanism involving MSCs. J Orthop Res 2011;29(12):1795-1803

24 Miyazono K. Positive and negative regulation of TGF-beta signaling. J Cell Sci 2000;113(Pt 7):1101-1109

25 Zhao L, Jiang S, Hantash BM. Transforming growth factor beta1 induces osteogenic differentiation of murine bone marrow stromal cells. Tissue Eng Part A 2010;16(2):725-733

26 Alberto C, De Carvalho RS, Francischone CE, Consolaro MF, Francischone CE. Saucerization of osseointegrated implants and planning of simultaneous orthodontic clinical cases. Dental Press J Orthod 2010;5:19-30

27 Kurten RC, Chowdhury P, Sanders RC, Jr, et al. Coordinating epidermal growth factor-induced motility promotes efficient wound closure. Am J Physiol Cell Physiol 2005;288(1):C109-C121
28 Govoni KE. Insulin-like growth factor-I molecular pathways in osteoblasts: potential targets for pharmacological manipulation. Curr Mol Pharmacol 2012;5(2):143-152

29 Kawazoe T, Kim HH. Tissue augmentation by white blood cell-containing platelet-rich plasma. Cell Transplant 2012;21(2)(3):601-607

30 Dohan Ehrenfest DM, Rasmusson L, Albrektsson T. Classification of platelet concentrates: from pure platelet-rich plasma (P-PRP) to leucocyte- and platelet-rich fibrin (L-PRF) Trends Biotechnol 2009;27(3):158-167

31 Dohan Ehrenfest DM, Del Corso M, Inchingolo F, Sammartino G, Charrier JB. Platelet-rich plasma (PRP) and platelet-rich fibrin (PRF) in human cell cultures: growth factor release and contradictory results. Oral Surg Oral Med Oral Pathol Oral Radiol Endod 2010;110(4):418-421, author reply 421-422

32 Anitua E, Andia I, Ardanza B, Nurden P, Nurden AT. Autologous platelets as a source of proteins for healing and tissue regeneration. Thromb Haemost 2004;91(1):4-15

33 Anitua E, Sánchez M, Orive G, Andía I. The potential impact of the preparation rich in growth factors (PRGF) in different medical fields. Biomaterials 2007;28(31):4551-4560

34 Li Q, Pan S, Dangaria SJ, et al. Platelet-rich fibrin promotes periodontal regeneration and enhances alveolar bone augmentation. BioMed Res Int 2013;2013:638043

35 Kumar RV, Shubhashini N. Platelet rich fibrin: a new paradigm in periodontal regeneration. Cell Tissue Bank 2013;14(3):453-463

36 Arosa F, Cardoso E, Pacheco F, Immunology Fundamentals. 2nd ed. Lisbon: Lidel Technical Editions Limited; 2012

37 Dohan DM, Choukroun J, Diss A, et al. Platelet-rich fibrin (PRF): a second-generation platelet concentrate. Part III: leucocyte activation: a new feature for platelet concentrates? Oral Surg Oral Med Oral Pathol Oral Radiol Endod 2006b;101(3):e51-e55

38 Hart J. Inflammation. 1: Its role in the healing of acute wounds. J Wound Care 2002;11(6):205-209

39 Di Liddo R, Bertalot T, Borean A, et al. Leucocyte and platelet-rich fibrin: a carrier of autologous multipotent cells for regenerative medicine. J Cell Mol Med 2018;22(3):1840-1854

40 Dohan Ehrenfest DM, Bielecki T, Jimbo R, et al. Do the fibrin architecture and leukocyte content influence the growth factor release of platelet concentrates? An evidence-based answer comparing a pure platelet-rich plasma (P-PRP) gel and a leukocyte- and platelet-rich fibrin (L-PRF) Curr Pharm Biotechnol 2012;13(7):1145-1152

41 Zafar MS, Khurshid Z, Almas K. Oral tissue engineering progress and challenges. Tissue Eng Regen Med 2015;12:387-397

42 Aggour RL, Abd El-Hady HM. Platelet-rich fibrin for the treatment of intrabony periodontal defects in patients with generalized aggressive periodontitis: A randomized controlled clinical study. J Int Acad Periodontol 2017;19:28-34

43 Kobayashi E, Flückiger L, Fujioka-Kobayashi M, et al. Comparative release of growth factors from PRP, PRF, and advancedPRF. Clin Oral Investig 2016;20(9):2353-2360

44 Marrelli M, Paduano F, Tatullo M. Human periapical cyst-mesenchymal stem cells differentiate into neuronal cells. J Dent Res 2015;94(6):843-852

45 van Hinsbergh VW, Collen A, Koolwijk P. Role of fibrin matrix in angiogenesis. Ann N Y Acad Sci 2001;936:426-437

46 Del Corso M, Vervelle A, Simonpieri A, et al. Current knowledge and perspectives for the use of platelet-rich plasma (PRP) and platelet-rich fibrin (PRF) in oral and maxillofacial surgery part 1: periodontal and dentoalveolar surgery. Curr Pharm Biotechnol 2012;13(7):1207-1230

47 Miron RJ, Zucchelli G, Pikos MA, et al. Use of platelet-rich fibrin in regenerative dentistry: a systematic review. Clin Oral Investig 2017;21(6):1913-1927 
48 Najeeb S, Khurshid Z, Agwan MAS, Ansari SA, Zafar MS, Matinlinna JP. Regenerative potential of platelet rich fibrin (PRF) for curing intrabony periodontal defects: a systematic review of clinical studies. Tissue Eng Regen Med 2017;14(6):735-742

49 Maluf G, Caldas RJ, Silva Santos PS. Use of leukocyte - and platelet-rich fibrin in the treatment of medication-related osteonecrosis of the jaws. J Oral Maxillofac Surg 2018;76(1):88-96

50 Masoudi E, Ribas J, Kaushik G, Leijten J, Khademhosseini A. Platelet-rich blood derivatives for stem cell-based tissue engineering and regeneration. Curr Stem Cell Rep 2016;2(1):33-42

51 Dohan Ehrenfest DM, Pinto NR, Pereda A, et al. The impact of the centrifuge characteristics and centrifugation protocols on the cells, growth factors, and fibrin architecture of a leukocyte- and platelet-rich fibrin (L-PRF) clot and membrane. Platelets 2018;29(2):171-184

52 Rock L. Potential of platelet rich fibrin in regenerative periodontal therapy: Literature review. Can J Dent Hyg 2013;47:33-37

53 Del Corso M, Mazor Z, Rutkowski JL, Dohan Ehrenfest DM. The use of leukocyte- and platelet-rich fibrin during immediate postextractive implantation and loading for the esthetic replacement of a fractured maxillary central incisor. J Oral Implantol 2012;38(2):181-187

54 Clark D, Rajendran Y, Paydar S, et al. Advanced platelet-rich fibrin and freeze-dried bone allograft for ridge preservation: a randomized controlled clinical trial. J Periodontol 2018;89(4):379-387

55 ClinicalTrials.gov. National Library of Medicine(U.S.). Advanced Platelet Rich Fibrin in Periodontal Angular Defects. Identifier NCT03433066; 2018. Available at:https://www.clinicaltrials. gov/ct2/show/NCT03433066. Accessed December 19, 2018

56 Carragee EJ, Hurwitz EL, Weiner BK. A critical review of recombinant human bone morphogenetic protein-2 trials in spinal surgery: emerging safety concerns and lessons learned. Spine J 2011;11(6):471-491

57 Crisci A, Marotta G, Licito A, Serra E, Benincasa G, Crisci M. Use of leukocyte platelet (L-PRF) rich fibrin in diabetic foot ulcer with osteomyelitis (Three clinical cases report). Diseases 2018;6(2):E30 